\title{
A systematic classification of student misconceptions in biological evolution
}

\author{
Pratchayapong Yasri
}

PhD, Mahidol University, Institute for Innovative Learning, 999, Phuttamonthon 4 Road, Nakhon Pathom, 73170, Thailand, E-mail: pratchayapong.yas@mahidol.ac.th

\begin{abstract}
The paper considers student understandings of particular aspects of biological evolution from the perspective of misconceptions. Although lists of misconceptions and possible categories have been proposed in educational research studies, individual misconceptions have not been categorised systematically. This paper therefore explores student misconceptions in biological evolution in greater detail. It synthesises existing categorisation schemes for misconceptions and categorise each misconception within a synthesised scheme. According of this new scheme, student misconceptions in biological evolution can be systematically classified into five groups: common sense, content-based, NOS-based (misconceptions related to the nature of science), non-scientific and vernacular misconceptions. This categorisation serves as an organisational scheme for future research on student misconceptions in evolutionary theory, providing both fundamental and analytical frameworks for researchers interested in biology education.
\end{abstract}

Key words: misconceptions, evolution, classification, biology education 


\section{Fundamental scientific concepts of biological evolution}

This section reviews fundamental concepts of biological evolution as explained by scientists and science educators. The review aims to present a standard understanding of the theory of biological evolution which is later used to compare with student misconceptions in biological evolution. To begin with the definition of evolution, Scott (2004, p. 23) defines the term evolution broadly as "a cumulative change through time", pointing out that there are various meanings of evolution including astronomical, geological, chemical and biological evolution. However, in this paper, the term evolution is limited only to the strand of biological evolution. Wiles (2010, p. 18) defines this as the explanation for "the diversity of life on Earth [which] has arisen via descent with modification from a common ancestry" (p. 18). Scott (2004, p. 27) specifically explains that biological evolution is not the explanation of the origin of life itself but "the descent of living things from ancestors from which they differ" (p. 27). Taking her broad and specific definitions together, Scott (2004, p. 27) comments that "descent with modification through time" is an effective explanation of biological evolution.

Instead of focusing on defining the term evolution, Alexander (2009) distinguishes between three main aspects of biological evolution: evolutionary devices (i.e. DNA and genes), evolutionary mechanisms (i.e. natural selection and reproductive success) and the result of their combination in the form of macroevolution (i.e. speciation and fossils). These aspects are relevant to five core aspects of biological evolution guided by Biological Sciences Curriculum Study (2005) which are suggested as important to introduce to high school students in the US, consisting of how species evolve over periods of time, how species evolve from common ancestors, how new forms of species derive from existing species (speciation), how evolutionary processes gradually occur, and how natural selection plays a major role in the evolutionary mechanism. Indeed, these are aspects originally contributed by Charles Darwin (1859) and elaborated in his book entitled the Origin of Species by Means of Natural Selection, but which have been developed through the advanced knowledge of genetics and molecular biology (Jablonka \& Lamb, 2014).

As a consequence of Darwin's book, the term natural selection has been widely used. Among biological scientists, this process is generally "considered to be the most powerful source of evolutionary change" (Scott, 2004, p. 34). Pongsophon (2006) points out that high school students in Thailand are required to understand five sequential steps of the mechanism of natural selection: the origin of genetic variation (alterations of genetic information of inherited traits within a population), the role of genetic variation (unpredictable outcomes which can lead to either beneficial, neutral or harmful traits depending on certain environmental conditions), change in a population trait (those having traits that are beneficial in a particular environment achieve higher reproductive rates and become dominant), the role of environment (environmental conditions as selective agents), and speciation (the emergence of distinct species resulting from the accumulation of genetically isolated populations of a single species over time).

Apart from the in-depth consideration of what biological evolution means and is about, Smith (2010) suggests that it is also important for students to understand what evolution is not; and thus he points out three essential points. First, evolution is not a discipline of faith. In other words, the science of evolution focuses on the natural world and questions relating to 
supernatural powers are beyond its scope. Second, like Scott (2004), Smith (2010) argues that biological evolution explains the origin of species from ancestral species, not the origin of the first living organisms. In other words, there are scientific distinctions between the theory that explains the origin of life (abiogenesis) and the theory that explains the origin of biodiversity of life forms (biological evolution). Third, biological evolution is emergent, not directional. Therefore, teleological thinking which concerns purposes of evolutionary events is not an aspect of consideration based on scientific perspectives. In addition, Smith (2010) provides an extensive list of common misconceptions derived from a review of the existing literature. This list forms the basis for the study described in this paper, and is discussed in the next section.

\section{Misconceptions in science}

Eggen and Kauchak (2004) explain that concepts can be considered as ideas that help us make sense or understand the world around us. Thus misconceptions are preconceived notions that provide some sorts of understanding but that are not in line with justified knowledge (Martin et al., 2002). Thompson and Logue (2006) note that there are possible ways for learners to develop misconceptions such as through parents (e.g. they might be confronted with questions from their children, and rather than admitting that they are unable to answer, they might give an incorrect answer), through media (e.g. learners may consult online sources of information that they perceive as "trustworthy" but they may not provide correct information), or through teachers (e.g. learners may perceive teachers as their cognitive authority and fully accept what they explain or believe as correct information), among others.

Using the language of misconceptions might be considered as a "bad" way of describing student conceptions through the implication that these are "wrong", which is relatively negative and may appear judgmental. However, judging student understandings as "right" and "wrong" may not be helpful in any ways (Hokayem \& BouJaoude, 2008). Therefore, the working definition of misconceptions in science used throughout this paper is limited to alternative frameworks or ideas about the world perceived by learners that are different from the accepted scientific ideas (Allen, 2010). Thus misconceptions are simply those ideas that contrast with accepted scientific accounts (whether or not these are factually "correct").

In order for biology teachers to help their students develop a scientific understanding of biological evolution, it is important to identify which ideas about evolution constitute misconceptions (Committee on Undergraduate Science Education National Research Council, 1997). Smith (2010) highlights a series of misconceptions in biological evolution and the nature of science related to the theory of evolution reported in empirical studies. He presents them in five themes: those generated from personal experiences (e.g. genetic mutations are always detrimental to fitness such as those that cause cancers and physiological malfunctions), those constructed by learners based on different stages of their conceptual development of scientific reasoning (e.g. teleological thinking that evolution is function and/or purpose directed), those caused by poor science education (e.g. Lamarckian misconceptions and misunderstanding of the nature of science), those arising from misuse of everyday spoken terms (e.g. theory versus law), those related to religious claims (e.g. young earth creationist beliefs).

Mapping Smith (2010)'s themes of misconceptions about biological evolution onto a 
standard classification of misconceptions about science proposed by the Committee on Undergraduate Science Education National Research Council (1997), a similarity is found. The Committee on Undergraduate Science Education National Research Council (1997) classify misconceptions about science into five groups: preconceived notions, non-scientific beliefs, vernacular misconceptions, conceptual misconceptions and factual misconceptions. Although this classification is used to explain misconceptions in science in general (no examples of biological evolution are given in the original text), it can be applied to the theory of evolution and the misconceptions compiled by Smith (2010) appropriately.

\section{A synthesised classification of misconceptions in biology education}

This section proposes a systematic classification of misconceptions about biological evolution based on the categorical schemes discussed by the Committee on Undergraduate Science Education National Research Council (1997) and Smith (2010). The need for this is that no classification of misconceptions of biological evolution has been provided in the literature. Although Smith (2010) proposes the five themes of misconceptions (from experience misconceptions, self-constructed misconceptions, taught-and-learned misconceptions, vernacular misconceptions, and religious misconceptions), he does not explicitly and systematically classify the misconceptions themselves, and does not discuss in the main text in his paper how these themes arose. They are only shown in the summary table where the misconceptions are presented (pp. 552-553), and grouping might be for the purpose of readability. Having noted that, Smith (2010)'s themes are considered as a very good starting point. Therefore, based on his work and the classification of misconceptions in science in general by the Committee on Undergraduate Science Education National Research Council (1997), a systematic classification of misconceptions about biological evolution and the nature of science related to the theory of evolution is proposed here (see Table 1). Justifications for reorganisation of the two schemes for grouping misconceptions are discussed in the following paragraphs. Selected terminologies to define each group of the proposed classification are also introduced.

Table 1. Classifications of misconceptions about biological evolution

\begin{tabular}{|c|c|c|}
\hline Smith (2012b) & $\begin{array}{l}\text { Committee on Undergraduate } \\
\text { Science Education National } \\
\text { Research Council (1997) }\end{array}$ & $\begin{array}{l}\text { A proposed } \\
\text { categorisation for } \\
\text { future use }\end{array}$ \\
\hline $\begin{array}{l}\text { From-experience misc. } \\
\text { Self-constructed misc. }\end{array}$ & Preconceived notions & Common sense misc. \\
\hline Vernacular misc. & Vernacular misc. & Vernacular misc. \\
\hline Religious misc. & Non-scientific beliefs & Non-scientific misc. \\
\hline $\begin{array}{l}\text { Taught-and-learned misc. } \\
\text { (group 1) }\end{array}$ & $\begin{array}{l}\text { Conceptual misc. } \\
\text { Factual misc. }\end{array}$ & Content-based misc. \\
\hline $\begin{array}{l}\text { Taught-and-learned misc. } \\
\text { (group 2) }\end{array}$ & - & NOS-based misc. \\
\hline
\end{tabular}


First, two themes presented by Smith (2010) including from experience misconceptions and self-constructed misconceptions are well captured by the definition of preconceived notions presented by the Committee on Undergraduate Science Education National Research Council (1997). These all seem to refer to ideas constructed by individuals' common sense based on daily life activities. Although minor variations in definitions can be further discussed, these previously proposed themes seem to have a common ground in terms of the use of personal experiences to construct one's own knowledge of a given phenomenon. In this paper, it is therefore considered as more sensible to combine them together and they are now called common sense misconceptions.

Second, whereas the Committee on Undergraduate Science Education National Research Council (1997) differentiate conceptual misconceptions from factual misconceptions, Smith (2010) combines them in the theme of taught-and-learned misconceptions. However, in order to frame the discussion on the ground of its simplicity, the latter work is preferably chosen in this study. This is due to the fact that conceptual misconceptions and factual misconceptions, at least in the context of biological evolution are unlikely to be completely separate. It is likely that the main difference between conceptual and factual misconceptions is the "seriousness" of misunderstanding. Conceptual misconceptions are recognised by the Committee on Undergraduate Science Education National Research Council (1997) as preconceptions about particular theories that have never been replaced by accurate scientific explanations. In contrast, factual misconceptions are falsities held by learners which remain unchanged through time.

In order to elaborate this distinction in the light of biological evolution, two obvious examples are given. While Lamarckian ideas of evolution constitute conceptual misconceptions, belief that man evolved from monkeys or modern apes associates with factual misconception. Although scientifically invalid, the former relatively seems to be more sophisticated, whereas the latter is considered to be relatively simplistic. However, the distinction between these kinds of misconceptions is unclear and in fact problematic. For example, one is obliged to determine which conceptions are "simplistic" versus "sophisticated", or to decide whether conceptions might change over time or not. These appear ill-defined. Therefore, it is argued in this paper that these two groups should be combined into one, and the new group shall be called content-based misconceptions.

Finally, Smith (2010) conflates misconceptions related to contents of biological evolution with misconceptions related to the nature of science associated with evolution in his taught-and-learned misconceptions, although he himself explicitly notes in the summary table which misconceptions are considered to be particularly related to the nature of science. In science education research, these two types of misconceptions are often studied separately. This paper therefore argues that content-based misconceptions and misconceptions related to the nature of science are distinct. The term adopted here for the latter is NOS-based misconception, where NOS stands for nature of science. This abbreviation will be use throughout this paper from this point onwards.

\section{Student misconceptions in biological evolution}

In this section, student misconceptions in biological evolution and the nature of science related 
to the theory of evolution will be reviewed according to the proposed classification discussed in Section 3. Examples used in the discussion below are drawn from a number of papers addressing student misconceptions in biological evolution. The aim of this is primarily to provide the theoretical framework of future development of the body of research in student misconceptions about biological evolution.

\section{Common sense misconceptions}

Common sense misconceptions are ideas that arise from experiences in daily life activities, according to the Committee on Undergraduate Science Education National Research Council (1997). Learners appear to link their experiences with natural phenomena and construct their own understanding about them based on personal rationalisation. For example, many learners think that evolution usually occurs in a purposeful direction starting from lower taxonomical species towards higher ones (Alter and Nelson, 2002, Smith, 2010, González Galli and Meinardi, 2011). González Galli and Meinardi (2011, p. 147) refer to these ideas as "common sense teleology", explained as the misuse of science to explain that something exists for a particular purpose based on non-scientific ways of thinking.

Another misconception based on common sense is an argument from design. According to this argument, the orderliness apparent in the biological world, commonly referred to as the "design", such as biochemical pathways in living cells, structural units of biochemical molecules, the complexity of organ systems, and physiological functions of living organisms, provides evidence for the existence of an intelligent designer (Fuller, 2007). A classic example of this argument is taken from William Paley who compares the complexity of living things to the complexity of a watch, which is known to be designed. The teleological argument specifically made for this analogy is that just as a watch could not exist without a watchmaker, living things could not exist without an intelligent designer (Finlay, 2004). However, this argument is opposed by scientists because the complexity of the biological world can be explained through random mutation and natural selection according to Neo-Darwinian evolution (Alexander, 2009). González Galli and Meinardi (2011, p. 147) argue that designrelated misconceptions are an obstacle to evolution learning.

\section{Content-based misconceptions}

In this study, content-based misconceptions are any ideas perceived by individuals that contradict the fundamental concepts of biological evolution described in Table 2. Three main content-based misconceptions are predominantly discussed in the literature composing of the theory of acquired inheritance, known as Lamarckian inheritance (Pongsophon, 2006), the topic of the origin of living cells according to the theory of abiogenesis (Rice et al., 2010), and human evolution.

Focusing on Lamarckian inheritance, Pongsophon (2006) explains that many students believe that changes in individual organisms are made by the organisms themselves and they can pass these characteristics on to their offspring. However, Gregory (2009, p. 169) explains that physical changes that occur during an organism's lifetime cannot be passed on to offspring. This is because the cells that are involved in reproduction (the germ line) are distinct from those that make up the rest of the body (the somatic line); only changes that affect the germ line can be passed on. 
Building from this misconception, many form the idea that evolution is a needs-based process and that animals have to evolve in order to survive. For them, evolution is understood to occur in a linear direction starting from the less adaptive species towards the more adaptive ones (Alter and Nelson, 2002, Smith, 2010, González Galli and Meinardi, 2011). However, the current knowledge from population genetics explains that the perceived direction of evolution is the consequence of the reproductive success (or fitness) of populations, not physical adaptation through a need-based process of individual organisms (Stearns and Hoekstra, 2005). In small populations, drift is also an important factor determining evolutionary outcomes.

Another example of content-based misconceptions is related to the confusion between abiogenesis and biological evolution (Smith, 2010). When considering the term biological evolution, many appear to view it holistically as the biological history of life, starting from the origin of the first molecules of life and the first living cell, the development of multicellular organisms, to the emergence of higher taxonomical animals and human beings. In fact, scientific explanations differentiate between the processes by which life arose from non-living matter and those by which life developed into the diverse forms recognised today: the former processes are those of abiogenesis; the latter are explained by evolutionary theory (Rice et al., 2010). Smith (2010, p. 542) notes that "in the strictest sense, Darwinian evolution is an explanation of the origin of species from ancestral species, not the origin of the first living thing" (p. 542).

A few more examples of content-based misconceptions related to human evolution are found in empirical studies with students. Clores and Limjap (2006) report that one of their student participants believed that humans evolved from monkeys. This is also the case in Yasri and Mancy (2014)'s study. This looks like a fairly obvious sign of misconceptions about human evolution (Stringer, 2012). To be more scientifically accurate, humans share a common ancestor with modern apes, like gorillas and chimpanzees. Nonetheless, it is possible that the learners involved in these studies failed to distinguish between monkeys and other apes (including our shared proto-ape ancestor with other modern apes), in which case the misunderstanding is in taxonomic vocabulary as opposed to evolutionary processes. Finally, Nehm and Schonfeld (2007) report that their participants believed that evolutionary theory demonstrates coexistence between humans and dinosaurs. However, Pickrell (2006) responds sarcastically to this view that "dinosaurs and people coexist only in books, movies and cartoons. The last dinosaurs - other than birds - died out dramatically about 65 million years ago, while the fossils of our earliest human ancestors are only about 6 million years old".

\section{NOS-based misconceptions}

Turning to misconceptions in biological evolution with regard to the nature of science, as the Biological Sciences Curriculum Study (2005) argues, scientific theories should not be studied in isolation from the ways in which the theories have been developed. Therefore, the nature of science becomes an important area of science instruction of concern to science educators (AbdEl-Khalick, 2012, Dagher and BouJaoude, 2005). Alongside the mainstream of research in the generic domain of the nature of science, student perceptions of the nature of evolutionary theory in particular have been investigated.

For example, Dagher and BouJaoude (2005) propose different aspects of the nature of 
science related to biological evolution that college biology students tend to misunderstand. First, the students sometimes considered that no "solid" evidence to validate the theory of evolution. Second, they sometimes wrongly perceived the certainty of the theory of evolution by expressing two radical views towards the degree of certainty. Some viewed that the theory of evolution is unchanging, whereas others considered that it remains uncertain and will be changed. Third, some students believed that no experimental investigations can directly test macroevolution and that experiments are required for science. Fourth, they consider that the development of the theory of evolution is ambiguous as some steps of the scientific method are missing; however, no explanation is given by the students which steps these are.

\section{Non-scientific misconceptions}

Non-scientific misconceptions refer to different views perceived by individual learners based on external sources other than science. Smith (2010) specifically points out that the major form of this kind of misconceptions is associated with religious beliefs. In relation to the theory of evolution, Scott (2004) classifies a range of positions in which religious beliefs are used to explain the scientific knowledge of the origin of life and biodiversity such as flat eartherism, geocentrism, young earth creationism, gap creationism, day-age creationism and progressive creationism. More broadly, a range of views for relating scientific and religious perspectives are identified both from philosophical (Yasri et al., 2013) and empirical perspectives (Yasri \& Mancy, 2014).

While many authors argue that these creationist/religious perspectives are misconceptions (e.g. Pongsophon, 2006, Scott, 2004, Williams, 2009), Reiss (2009a) asserts that teachers should think of these as student worldviews rather than mere misconceptions. Taking the assertion of Reiss (2009a), it is argued in this paper that religious beliefs have their own values and should not be judged as either right or wrong, especially not "en masse" in the sense of constituting misconceptions. However, it is undeniable that there are different sets of religious beliefs that obviously contradict scientific discoveries (Yasri et al. 2013; Yasri \& Mancy, 2014) and thus it is possible to consider these beliefs as misconceptions, at least from a scientific point of view. For example, the young-earth creationist claim that the world is only about 6000-10000 years old, has been shown to be factually incorrect by strong and coherent evidence in the geological sciences. However, to be explicit that there is no intention to make claims against religious beliefs in general in this study, the term used to describe this group of misconceptions is non-scientific misconceptions.

To elaborate a little, misconceptions can be understood as alternative ideas that may not be ontologically false, but for which there is no evidence (Allen, 2010). For example, to claim that the world is designed might be true, but science cannot show that to be the case. Also, and perhaps more subtly, the claim that biological complexities are the results of intelligent design might be a true statement, but these complexities can be explained by science without recourse to the notion of a designer (Fuller, 2007). Thus repeating itself again, misconceptions as considered in this paper are "scientific misconceptions" and include alternative ideas that cannot or have not been demonstrated scientifically, that go beyond scientific claims.

\section{Vernacular misconceptions}

According to the Committee on Undergraduate Science Education National Research Council 
(1997), vernacular misconceptions stem from the use of particular words that are understood differently between everyday life and scientific expressions. In other words, there are a number of terms that are used differently between members of the public and members of the scientific community. For example, Scott (2005) argues that, in everyday use, a "theory" means a guess. In science, a theory is not a guess, but "a logical construct of facts and hypotheses that attempts to explain a natural phenomenon" (p. 241). Therefore, saying that "evolution is just a theory" is a vernacular misconception used to reject evolution on the ground of disbelief rather than logical arguments.

Another example is given by Mead and Scott (2010) in relation to the use of terms chance and randomness. Among the scientific community, both are used in the fashion of statistical explanations. In science, the chance that something will happen means that it will occur according to a known probability. For example, the chance of having a child who has a type $\mathrm{O}$ blood from a mother having $\mathrm{AO}$ and a father $\mathrm{BO}$ alleles is one in four. Randomness is normally used in the sense of being governed by equal probability. For example, within a population mating system, every female gamete might be assumed to have an equal opportunity of being fertilised by every male gamete.

In contrast, the general public and students may interpret these terms differently. Mead and Scott (2010) explain that both of the terms are used non-probabilistically among students. Generally, Mead and Scott (2010) argue that many students misuse the terms by conflating random with purposelessness and chance with directionlessness. Often, those rejecting evolution rely on these vernacular misconceptions to spread their objections to evolution. For example, they contrast the terms chance and randomness with design in nature (i.e. Paley's analogy of the watchmaker). In this paper, although it is acknowledged that students may understand the terms scientifically, it is assumed that Mead and Scott (2010) may be right that, in general, students use them non-scientifically and towards rejection of evolution.

\section{Summary}

Based on the existing literature on biology education, this paper presents that student misconceptions in biological evolution can be systematically classified into five groups: common sense misconceptions, content-based misconceptions, misconceptions related to the nature of science, non-scientific misconceptions and vernacular misconceptions. The categorisation serves as an organisational scheme for future researchers in the filed biology education. It allows researchers to analyse and interpret findings on patterns of student misconceptions more easily and systematically. However, it is acknowledged that finding a categorisation structure and classify individual misconceptions in a way that is entirely objective or clear-cut is difficult. This paper also calls for empirical uses of this scheme in biology education research in order to validate its generalizability and usefulness. In addition, constructive modifications for future developing this scheme are encouraged to advance current understanding on student misconceptions in biological evolution.

\section{References}

Abd-El-Khalick, F. (2012). Examining the Sources for our Understandings about Science: Enduring conflations and critical issues in research on nature of science in science education. International Journal of Science Education, 34, 353-374. 
Allen, M. (2010). Misconceptions in primary science. Berkshire, Open University Press.

Alexander, D. (2009). Creation or evolution: Do we have to choose?, Oxford, Monarch Books.

Alter, B. J. \& Nelson, C. E. (2002). Perspective: teaching evolution in higher education. Evolution, 56, 18911901.

Biological Sciences Curriculum Study (2005). The nature of science and the study of biological evolution, Washington DC, NSTA Press.

Clores, M. \& Limjap, A. (2006). Diversity of students' beliefs about biological evolution. Asia Pacific Journal of Education, 26, 65-77.

Committee on Undergraduate Science Education National Research Council (1997). Science Teaching Reconsidered: A Handbook, Washington DC, The National Academies Press.

Dagher, Z. R. \& Boujaoude, S. (2005). Students' perceptions of the nature of evolutionary theory. Science Education, 89, 378-391.

Darwin, C. (1859). On the Origin of Species, London, John Murray.

Eggen, P. \& Kauchak, D. (2004). Educational Psychology: Windows, Classrooms, Upper Saddle River, Pearson Prentice Hall.

Finlay, G. (2004). Evolving creation. Auckland, TELOS Books.

Fuller, S. (2007). Science vs Religion? Intelligent design and the problem of evolution. Cambridge, Polity Press.

González Galli, L. \& Meinardi, E. (2011). The Role of Teleological Thinking in Learning the Darwinian Model of Evolution. Evolution: Education and Outreach, 4, 145-152.

Gregory, T. (2009). Understanding Natural Selection: Essential Concepts and Common Misconceptions. Evolution: Education and Outreach, 2, 156-175.

Hokayem, H., \& BouJaoude, S. (2008). College students' perceptions of the theory of evolution. Journal of Research in Science Teaching, 45(4), 395-419.

Jablonka, E., \& Lamb, M. J. (2014). Evolution in Four Dimensions, revised edition: Genetic, Epigenetic, Behavioral, and Symbolic Variation in the History of Life. MIT press.

Mead, L. \& Scott, E. (2010). Problem Concepts in Evolution Part I: Purpose and Design. Evolution: Education and Outreach, 3, 78-81.

Nehm, R. H. \& Schonfeld, I. (2007). Does increasing biology teacher knowledge about evolution and the nature of science lead to greater advocacy for teaching evolution in schools? Journal of Science Teacher Education, 18, 699-723.

Pickrell, J. (2006). Top 10: Dinosaur Myths. NewScientist.

Pongsophon, P. (2006). Enhancing Thai students' scientific understanding of evolution: A social constructivist approach. PhD Thesis, Kasetsart University.

Reiss, M. J. (2009). The relationship between evolutionary biology and religion. Evolution, 63, 1934-1941.

Rice, J. W., Warner, D. A., Kelly, C. D., Clough, M. P. \& Colbert, J. T. (2010). The theory of evolution is not an explanation for the origin of life. Evolution: Education and Outreach, 3, 141-142.

Scott, E. C. (2004). Evolution vs Creationism: An Introduction, California, University of California Press.

Smith, M. (2010). Current Status of Research in Teaching and Learning Evolution: II. Pedagogical Issues. Science \& Education, 19, 539-571.

Stearns, S. C. \& Hoekstra, R. F. (2005). Evolution, Oxford, Oxford University Press.

Stringer, C. (2012). Evolution: What makes a modern human. Nature, 485(7396), 33-35.

Thompson, F. \& Logue, S. (2006). An exploration of common student misconceptions in science. International Education Journal, 7, 553-559.

Wiles, J. (2010). Overwhelming scientific confidence in evolution and its centrality in science education and the public disconnect. Science Education Review, 9, 18-27.

Williams, J. D. (2009). Belief versus acceptance: why do people not believe in evolution? Bioessays, 31, 12551262.

Yasri, P. \& Mancy, R. (2014). Understanding student approaches to learning evolution in the context of their perceptions of the relationship between science and religion. International Journal of Science Education, 36(1), 24-45

Yasri, P., Arthur, S., Smith, M. U. \& Mancy, R. (2013). Relating science and religion: An ontology of taxonomies and development of a research tool for identifying individual views. Science \& Education, 22, 2679-2707. 


\section{Appendix}

Table 1. Summary of misconceptions and scientifically fundamental concepts of biological evolution and the nature of science related to evolution.

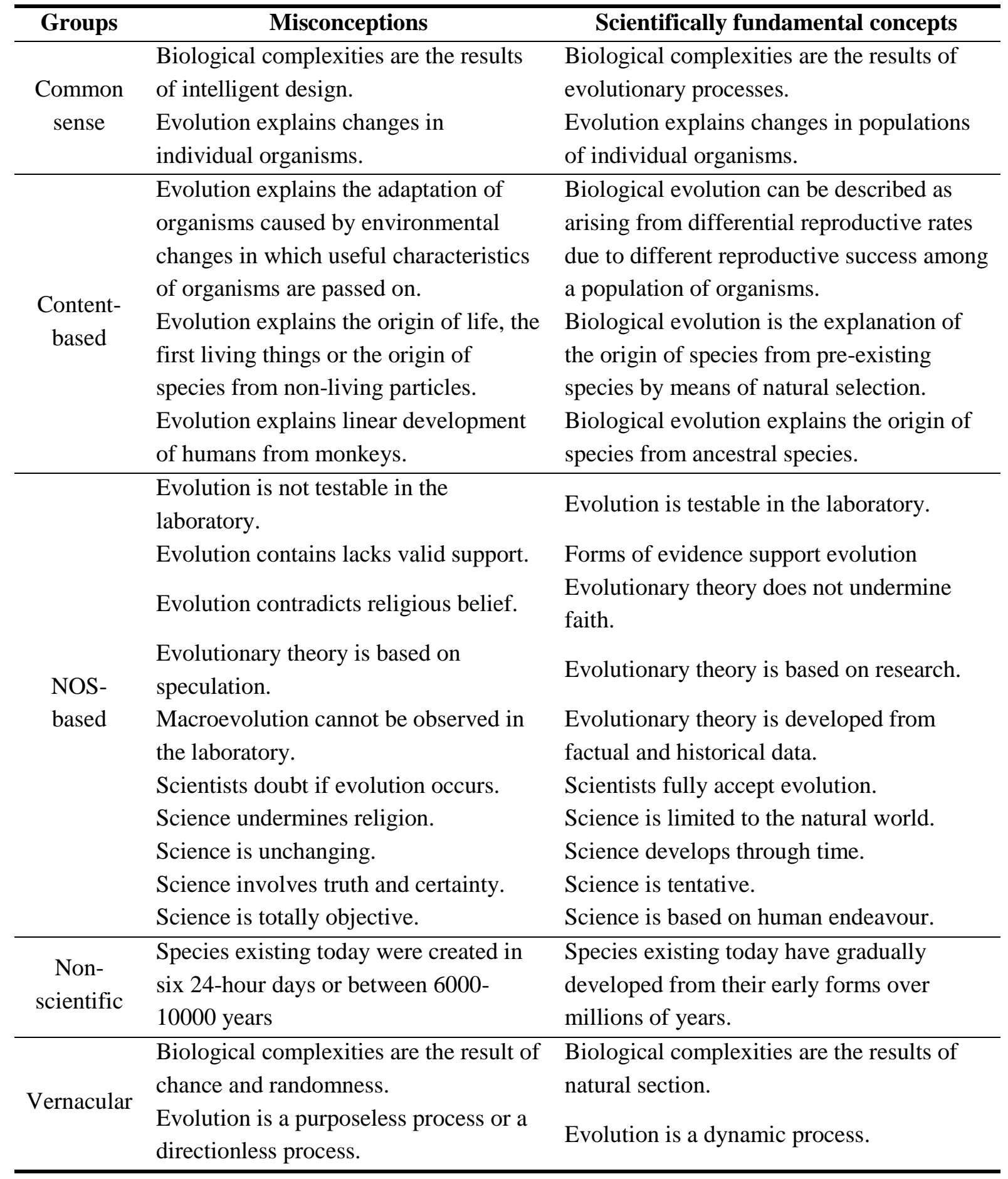

